\title{
Ensino de Programação no Ensino Médio: Uma Abor- dagem Orientada ao Design com a linguagem Scratch
}

Teaching Programming in High School: an approach guided by design with Scratch language

Pasqueline Dantas Scaico Universidade Federal da Paraíba pasqueline@dce.ufpb.br

\section{Silvia Azevedo}

Universidade Federal da Paraíba silvia.azevedo@dce.ufpb.br

\section{Yugo Alencar}

Universidade Federal da Paraíba yugo.alencar@dce.ufpb.br

\author{
Anderson Alves de Lima \\ Universidade Federal da Paraíba \\ anderson.alves@dce.ufpb.br
}

\section{Luiz Fernando Paiva}

Universidade Federal da Paraíba

fernando.paiva@dce.ufpb.br

\author{
João Paulo Mendes \\ Universidade Federal da Paraíba \\ paulo.mendes@dce.ufpb.br
}

\author{
Jefferson Barbosa Belo da Silva \\ Universidade Federal da Paraíba \\ jefferson.bello@dce.ufpb.br
}

\section{Ewerton Henning Raposo \\ Universidade Federal da Paraíba ewerton.raposo@dce.ufpb.br}

\author{
Alexandre Scaico \\ Universidade Federal da Paraíba \\ alexandre@dce.ufpb.br
}

Resumo Programação é algo extremamente importante e não deveria ser ensinada apenas para estudantes de Computação. Inúmeros fatores apontam a relevância de desenvolver competências relacionadas à programação com estudantes em idade escolar, que podem resultar em habilidades uteis para a resolução de problemas e a fluência no uso de tecnologias. Este trabalho apresenta a experiência obtida com um projeto que vem introduzindo o ensino de programação para alunos do ensino médio de escolas públicas, através de uma abordagem de ensino que estimula a criatividade e o poder de exploração que os jovens possuem. O artigo relata uma olimpíada de programação, atividade realizada para motivar os alunos, que serviu como ferramenta de avaliação.

Palavras-Chave: Ensino de programação orientado ao design, Scratch.

\begin{abstract}
Programming is extremely important and is an ability that should be taught not only to computer science students. Several aspects have shown the relevance of developing skills related to programming with students at school level, which may result in useful abilities regarding the resolution of problems and fluency in the use of technologies. This work presents an experience report regarding the results of a project to introduce programming to high school students from public schools, through a pedagogic approach that stimulates the creativity and exploration. This article describes a programming contest that was developed to motivate students and was used to evaluation.
\end{abstract}

Keywords: Teaching programming guided by design, Scratch. 


\section{Introdução}

A Computação evoluiu nas últimas décadas e concentrou esforços em diversas áreas de pesquisas que tornaram as tecnologias cada vez mais confiáveis e presentes no cotidiano das pessoas. Este panorama apresenta a Computação como uma área com grande potencial para gerar novos campos de atuação e, consequentemente, mais postos de trabalho. A Association for Computing Machinery (ACM) prevê que 120.000 empregos sejam abertos anualmente até 2020 apenas nos Estados Unidos e também que a escassez de graduados em Ciência da Computação (CC) aponta um cenário que pode ser um dos problemas mais graves enfrentados pela indústria de tecnologia [1].

Muitos estudos mostram que o desinteresse por parte dos estudantes por temas ligados à $\mathrm{CC}$ é reforçado pela existência de estereótipos e de informações imprecisas. Uma das causas desse comportamento pode ser atribuído ao fato de que, como a educação em Ciência da Computação não é um componente explorado nos currículos escolares, muitos estudantes possuem ideias incorretas e atitudes negativas sobre a área, percebendo como chatas e entediantes as carreiras neste campo.

Aprender a programar é extremamente importante. $\mathrm{O}$ desenvolvimento de algoritmos é o eixo central para todas as áreas relacionadas com a Computação, todavia, não deveria ser objeto de interesse apenas de estudantes de Computação. Inúmeros fatores apontam a relevância de desenvolver nos estudantes em idade escolar competências para a programação de computadores.

Em primeiro lugar, este tipo de educação permite o desenvolvimento de diversas capacidades que contribuem para melhorar o raciocínio lógico dos estudantes. Programar envolve a habilidade de desenvolver uma solução para um problema, que se for grande requererá o exercício de outras habilidades (como dividir o problema em subproblemas e criar uma solução central). Além disso, mais aproximação com essa área pode gerar uma influência importante para a escolha das carreiras dos adolescentes, que por vezes é realizada com base em informações imprecisas, o que os levam à frustração e, consequentemente, à evasão dos cursos superiores.

Outra razão para ensinar programação na escola é que tal proximidade pode contribuir para acertar a visão e as atitudes dos estudantes com relação à finalidade e o uso das tecnologias que habitualmente manuseiam. Sobre este assunto, Mitchel Resnick [2] traz uma reflexão interessante quando menciona que existe uma visão equivocada sobre a capacidade dos nativos digitais em relação ao uso de tecnologias. Para ele, os jovens gastam grande parte do seu tempo consumindo tecnologias (seja através das redes sociais ou dos jogos) mas isso não os tornam fluen- tes em tecnologia. Eles acabam desenvolvendo a capacidade de serem bons consumidores de informações, produzidas e filtradas através da tecnologia, mas não aprendem a produzir conhecimento novo, não sendo, portanto, indivíduos capazes de entender o potencial de criação existente através dos recursos tecnológicos que aí estão. Resnick chama atenção para a necessidade de repensar quais as competências realmente deveriam ser desenvolvidas nas escolas, para que em um futuro próximo se torne possível ensinar aos jovens a capacidade de criar e de se expressar, o que os preparará para a fluência em tecnologias. Ensinar os jovens a programar pode ser um ponto de partida desse processo.

Grande organizações têm reconhecido a importância de ensinar programação na educação básica. O Google tem investido muito em programas e projetos que estão lotados na divisão Google na Educação, desenvolvidos para incentivar a introdução dos conceitos da $\mathrm{CC}$ e estimular a prática do pensamento computacional com estudantes do ensino médio. Os projetos Computer Science on Air $^{l}$ e Computer Science for High School ${ }^{2}$ são duas dessas iniciativas. Outras ações vêm surgindo na Web, como é o caso do Codeacademy ${ }^{3}$, CoderDojo $^{4}$, Girls who Code $^{5}$ e Black Girls Code ${ }^{6}$, e têm popularizado as discussões em torno da necessidade de introduzir tais conteúdos no cotidiano dos adolescentes.

Muitos governos, a exemplo de países como a Estônia, que implantou um programa para o ensino de programação para alunos com idade a partir dos seis anos[3], os Estados Unidos [4] e a Nova Zelândia [5], têm se preocupado em formar essas competências porque entendem que isso gerará impactos nas suas economias e na capacidade que seus cidadãos terão para se adaptar às mudanças.

Dessa maneira, discutir este tema é de extrema importância. Todavia, introduzir este assunto merece muito esforço de planejamento, já que aprender a programar não é uma tarefa simples e a iniciação dos jovens a partir de abordagens equivocadas poderá gerar o efeito contrário ao que se pretende.

Programar requer o domínio de um conjunto amplo de habilidades técnicas, tais como: o conhecimento de linguagens de programação, de ambientes para a construção do código, de embasamento matemático, e de outras capacidades que estão mais relacionadas a aspectos cognitivos e psicológicos, a exemplo da habilidade de representar bem o problema e saber decompô-lo, de construir o seu significado, de criar modelos mentais que auxiliem a

\footnotetext{
${ }^{1}$ https://sites.google.com/site/eduonair/

${ }^{2}$ http://cs 4 hs.com

${ }^{3}$ http://www.codecademy.com

${ }^{4} \mathrm{http}: / /$ coderdojo.com/

${ }^{5} \mathrm{http}: / /$ www.girlswhocode.com/

${ }^{6} \mathrm{http}: / /$ www.blackgirlscode.com
} 
busca da solução, de abstrair conceitos e reconhecer padrões [6] [18]. Apesar de parecer difícil, experiências de sucesso mostram que pode ser possível introduzir o ensino de programação com estudantes em idade escolar, desde que estratégias e ferramentas adequadas sejam utilizadas.

Primordialmente, o ensino de programação para novatos deve ser acompanhado de uma metodologia que mantenha os estudantes engajados e motivados para que as dificuldades sejam superadas e eles continuem interessados em aprender. Neste contexto, além do procedimento metodológico, a utilização apropriada de uma linguagem de programação pode minimizar a inserção de erros no código, que são provenientes da inabilidade inicial dos novatos com a sintaxe, aspecto que pode contribuir para reduzir a ocorrência de situações que deixam os novatos desmotivados. Eliminar essas barreiras significa contribuir para que os alunos mantenham o esforço concentrado na construção dos algoritmos.

Então, reconhecendo a importância de ensinar programação no ensino médio através de um ambiente que possibilite experiências interessantes de aprendizagem, desenvolveu-se um projeto para introduzir o ensino de programação em escolas públicas localizadas no interior da Paraíba.

Este trabalho apresenta o relato dessa experiência que vem obtendo resultados positivos, tanto por utilizar uma abordagem que concentrou os esforços não apenas em ensinar uma linguagem de programação, quanto em estabelecer situações em que os alunos pudessem se interessar pela exploração de novos assuntos e reconhecer o poder de criação disponível através das tecnologias. Uma das principais ações do projeto culminou em uma olímpiada de programação interna, que apresentou resultados inspiradores.

Este trabalho está organizado da seguinte maneira: a Seção 2 apresenta um panorama geral sobre o ensino de programação na educação básica e procura explicar a motivação para a escolha da linguagem de programação utilizada. A Seção 3 descreve a metodologia que conduziu o planejamento e execução das atividades do projeto. A Seção 4 descreve em detalhes uma das principais ações do projeto: uma olimpíada de programação que explorou diversas capacidades dos alunos, que serviu para validar a metodologia de ensino utilizada e funcionou como um mecanismo de avaliação. Por fim, a Seção 5 apresenta as considerações finais e o estado atual do trabalho.

\section{Referencial Teórico}

\subsection{Ensino de programação}

A importância da disponibilidade e do uso de tecnologias para a geração atual dos estudantes é um fato.
Outro fato também é que possivelmente eles se envolverão com empregos que nem sequer existem hoje. Este cenário enfatiza a necessidade de oferecer uma educação que proporcione aos jovens, e aos futuros adultos, a habilidade de trabalhar com diferentes instrumentos produzidos pela Computação e de explorá-los a seu favor não apenas no campo da diversão e do entretenimento.

Alguns países vêm reconhecendo a necessidade de atualizar os seus sistemas educacionais no que se refere à educação em Computação. Nos Estados Unidos, o modelo que está sendo adotado chama atenção para conteúdos que permitem o alcance da chamada Educação Imperativa, que é aquela onde mais importante do que aprender temas ligados à tecnologia está a capacidade de desenvolver nos estudantes o pensamento computacional e a sua autonomia para a resolução de problemas [4].

$\mathrm{Na}$ academia, muitas revisões da literatura evidenciam a necessidade de ampliar os esforços dos pesquisadores no que se refere ao conhecimento que se possui sobre o porquê de ensinar Computação nas escolas, de como os conteúdos deveriam ser ensinados, que tópicos deveriam ser lecionados e para quem esta educação poderia ser significativa.

Em se tratando disso, muito interesse cerca um tópico específico: o ensino de programação, principalmente porque se reconhece a diferença entre saber programar e ser capaz de ensinar alguém a programar. Saeli [7] ressalta que o cenário de uma sala de aula é um ambiente complexo, onde muitos processos e ações estão acontecendo simultaneamente, e que é influenciado pelo estilo de aprendizagem dos alunos. Tratando desse aspecto, o autor identifica cinco dificuldades frequentes que podem provocar distúrbios na ação de ensinar e de aprender programação, os quais estão relacionadas a aspectos técnicos e motivacionais dos estudantes no que se refere a:

- Entender a utilidade da programação e os seus benefícios.

- Compreender as propriedades gerais de uma máquina (um computador, no caso) que o aluno está aprendendo a controlar.

- Aprender uma nova notação, que pode provocar problemas relacionados aos aspectos de sintaxe e semântica das linguagens de programação.

- Entender o uso correto das estruturas de programação.

- Atingir proficiência nas habilidades necessárias à implementação, sejam elas: especificar, codificar, depurar e testar o código.

Algumas abordagens de ensino têm sido discutidas na tentativa não apenas de prevenir dificuldades e mau en- 
tendimentos que os estudantes venham possuir, mas também de estabelecer um nível de motivação nos estudantes de forma efetiva e engajadora.

Em um nível global, muitos trabalhos relacionados ao ensino de programação com estudantes em idade escolar já foram relatados. Futschek e Moschitz[8] relata as suas experiências com o uso de estratégias de ensino de programação para crianças, que são baseadas em objetos tangíveis, as quais se mostraram capazes de diminuir a abstração para determinadas explicações e de estabelecer um ambiente motivador. Já Major et al [9] discorre sobre a sua experiência pedagógica através da utilização de uma ferramenta de ensino de programação baseada em um simulador de robôs.

Sobre este tema, outro fator bastante discutido é a adoção da linguagem de programação em cursos introdutórios. Muitos trabalhos apresentam linguagens de programação como Python sendo usadas nesses cursos, isto porque ela possui a sintaxe simples, blocos delimitados por endentação e feedbacks imediatos, conforme menciona [10]. Grandell [11] afirma que ensinar e compreender Python torna-se mais fácil e permite que a sintaxe não seja mais uma barreira para que os aprendizes construam os algoritmos. Marques et al [12] cita sua experiência ao conduzir uma oficina de introdução à programação com Python para alunos do ensino médio, em que diversos jogos foram codificados e mostra que o uso de jogos como base dos projetos da disciplina foi um fator motivacional. Porém, Rapkiewicz et al [13] afirma que Python ainda é uma linguagem complexa para os iniciantes, mesmo sendo mais simples que diversas outras linguagens, o que pode interferir na construção de projetos de programação que sistematizem o engajamento dos estudantes.

No mundo inteiro, uma linguagem que tem sido utilizada para prover experiências inovadoras de aprendizagem é a linguagem Scratch. Os trabalhos de [14] e [15] relatam como essa linguagem, que é diferente das linguagens convencionais, pode ser utilizada de maneira muito criativa para atingir o envolvimento dos estudantes.

No Brasil, poucos trabalhos relatam experiências obtidas com ações que conseguiram estabelecer cursos de programação cujo objetivo central era o de ensinar uma linguagem de programação através de estratégias pedagógicas que abrissem espaço para a criatividade dos participantes, e que pudesse funcionar como um recurso de apoio para a melhoria do raciocínio lógico e a aquisição de novos conhecimento.

Dessa maneira, as diversas experiências relatadas apresentam resultados do uso da linguagem Scratch em ambientes escolares de outros países, que possuem as mais diferentes abordagens para explorar a CC nos seus currículos, fato este que dificulta entender, apenas através de tais fontes, os impactos na aprendizagem de estudantes brasileiros que poderiam ser gerados com o ensino de programação.

Então, as experiências relatadas neste trabalho são pioneiras entre as iniciativas que dizem respeito ao ensino de programação orientado ao design para o ensino médio público do Brasil, principalmente porque a abordagem utilizada procurou explorar este paradigma de ensino, que apresenta a programação com uma habilidade possível, útil e que pode ser divertida para qualquer estudante. Em função de se ter utilizado a linguagem Scratch no projeto, ela é descrita na Seção 2.2

\section{2 A linguagem Scratch}

A educação está passando por um processo de transformações e muitas discussões têm surgido em torno dos métodos de ensino. Thomas e Brown [16], ao se deslocarem dos modelos tradicionais pedagógicos, reconhecem o saber e o fazer como ações importantes para a aprendizagem, mas introduzem o brincar como uma nova dimensão relevante para a educação.

As novas tecnologias, por sua vez, estabelecem espaços que permitem que o fluxo de aprendizagem se crie por meio da experimentação, que estimula as descobertas. Assim, o saber, o fazer e o brincar são comportamentos que interagem naturalmente naqueles espaços. Thomas e Brown também apontam a existência de uma nova cultura de aprendizagem que tem se firmado através de uma rede de informações que é praticamente infinita, pela qual pode se aprender sobre tudo, e onde, a partir de um espaço limitado e com regras, existem possibilidades ilimitadas de experimentação.

Muitas intervenções pedagógicas têm procurado incorporar o uso de tecnologias na educação na tentativa de se apropriar de um modelo de ensino capaz de se alinhar aos interesses dos alunos e que seja capaz de promover uma reforma na forma de pensamento. Essa busca também tem acontecido através do ensino de Computação.

Aprender uma linguagem de programação é uma tarefa desafiadora. Todavia, tornar o ensino de programação mais acessível para um maior número de indivíduos é algo importante porque é capaz de estimular muitas capacidades cognitivas e para que aquele que aprende possa aplicar as técnicas utilizadas na programação na resolução de diversos outros tipos de problemas, nas mais distintas profissões.

Segundo Kelleher e Pausch [18], desde o início dos anos 1960, pesquisadores tentam desenvolver linguagens de programação e ambientes com a intenção de tornar a programação acessível para um número maior de pessoas. A principal dificuldade encontrada pelos programadores iniciantes é a questão da sintaxe, pois eles precisam com- 
preender a linguagem que o computador entende e também o idioma, já que nem todas as sintaxes das linguagens de programação possuem a clareza suficiente para que um novato entenda a funcionalidade e o uso dos seus comandos. Esses autores também afirmam que é preciso simplificar a sintaxe das linguagens, para que estas fiquem mais próximas da linguagem natural.

$\mathrm{O}$ ambiente Scratch traz uma linguagem que contribui para a aprendizagem de programação através de um conceito inovador de desenvolvimento de código orientado ao design, que privilegia a Computação Criativa, expressão que é utilizada para reconhecer que o conhecimento e as práticas que os jovens precisam adquirir para criar software devem ser provenientes dos seus interesses pessoais. A linguagem também foi projetada para estimular o uso de uma abordagem de aprendizagem que é caracterizada por um estilo de engajamento iterativo, experimental e lúdico, em que os estudantes estão constantemente reavaliando suas decisões, explorando novos caminhos e imaginando novas possibilidades [17].

O Scratch é uma linguagem de sintaxe simples, orientada a blocos de montar, que produzem projetos que podem ser compartilhados com a comunidade de desenvolvedores e que, consequentemente, podem ser melhorados por outras pessoas [19]. Apenas para efeito de ilustração do potencial pedagógico dessa linguagem, no que se refere apenas ao uso da sua sintaxe, a Figura 1 é apre- sentada para ilustrar as diferenças existentes na construção de uma estrutura de repetição nas linguagens Scratch, Python e Pascal.

Ao analisar o trecho de código (Figura 1), percebe-se que o fato dos comandos Scratch se basearem em uma estrutura de blocos de montar, o aluno pode concentrar seu esforço na busca pela construção do algoritmo, o que nem sempre é o caso das outras duas linguagens, cuja sintaxe para o comando de repetição, por exemplo, requer uma série de detalhes que podem dificultar o processo de compilar o algoritmo.

Assim, é possível supor que uma parte do esforço esteja na correção da sintaxe e não na lógica de programação, o que pode ser um fator desmotivador para o aprendiz. Especialmente para a realidade das escolas públicas brasileiras, o Scratch também é bem mais adequado pelo fato de possibilitar o uso do idioma nativo do país, o português.

Dessa maneira, pode-se dizer que o caráter mais didático do Scratch projeta no aluno a possibilidade de ele se concentrar no exercício do pensamento algorítmico e na criatividade durante a construção das soluções. Não ter que se preocupar com questões que são importantes, mas acessórias à programação, como é o caso da correção de problemas de sintaxe, é algo que instiga o aluno iniciante a se empenhar mais na criação dos códigos.

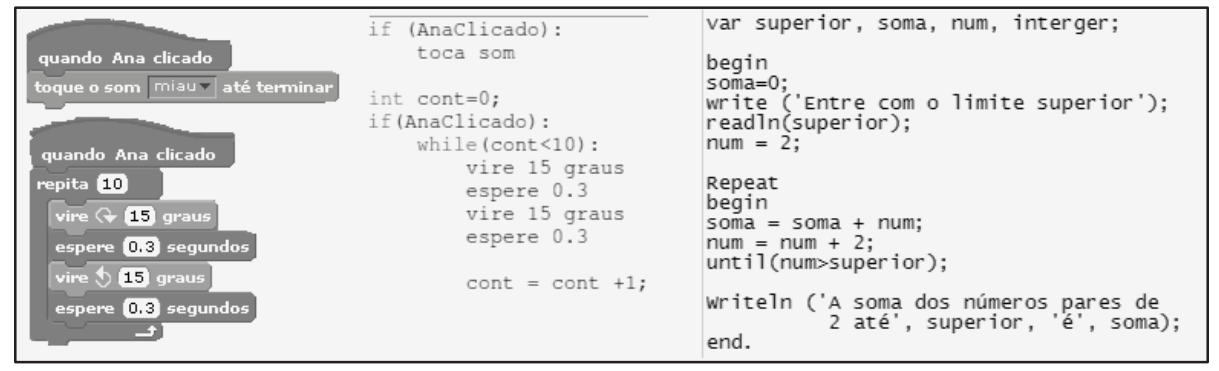

Figure 1: Apresentação de comando de repetição nas linguagens Scratch (esquerda), Python (centro) e Pascal(direita)

As aplicações construídas através do Scratch também podem interagir com o mundo real, através das informações que podem ser obtidas através de uma câmera ou de um microfone. Assim, o comportamento que pode ser produzido é algo semelhante ao que acontece nos jogos do Microsoft Kinect. Quando um jovem cria um projeto dessa natureza ele aprende a escrever código, mas mais importante é que ele está escrevendo código para aprender, porque esta é uma situação que abre espaço para muitas experiências de aprendizagem.

Dessa maneira, o potencial do Scratch está além de ser uma simples linguagem de programação porque é uma ferramenta de capaz de provocar a criatividade e o poder de exploração do programador e, principalmente, de criar situações capazes de lhes explicar o funcionamento das suas estruturas de uma maneira que lhe faça sentido. Por estas razões, Scratch foi a linguagem de programação utilizada no curso aqui descrito e cuja metodologia está detalhada na Seção 3.

\section{A metodologia utilizada}

O trabalho descrito neste artigo é o desdobramento de um projeto que vem sendo desenvolvido desde $2011 \mathrm{em}$ escolas públicas no interior da Paraíba, que tem como objetivo introduzir o pensamento computacional e algorítmico em escolas de ensino médio [20]. 
Antes de iniciarem o curso de programação, os estudantes participaram de diversas atividades que trataram de temas relacionados à tecnologia e que estimularam o pensamento computacional através de competições de equipe, a partir de atividades desplugadas [22]. Apesar desse contato, os estudantes não possuíam qualquer experiência prática com assuntos mais técnicos da Computação. Dessa maneira, a metodologia utilizada para introduzir o ensino de programação procurou estimulá-los a desenvolver pequenos softwares, como jogos simples e animações.

Foram utilizados alguns princípios de uma abordagem de ensino de programação que se baseia no conceito de design, que enfatiza:

- O poder de concepção do estudante, que o expõe a situações que exigem a produção de novas ideias a partir de um processo criativo, e não apenas a utilização (ou interação) de ideias previamente criadas por outras pessoas.

- A personalização dos elementos que serão construídos, na qual o estudante cria algo que é pessoalmente significativo e relevante.

- A necessidade de colaboração, que se manifesta através do trabalho em equipe e da discussão das ideias e soluções, e

- O poder da reflexão, no qual o estudante é estimulado a rever e repensar as práticas criativas na elaboração dos seus algoritmos.

Para assegurar que os estudantes teriam a atenção necessária em sala de aula, formaram-se quatro turmas contendo cada uma delas oito alunos, que ficaram sob a responsabilidade de uma dupla de professores. É válido mencionar que os professores eram estudantes do curso de Licenciatura em Computação da Universidade Federal da Paraíba, que estavam sendo supervisionados por um professor orientador. O público-alvo da primeira turma do curso de introdução à programação com Scratch foi um grupo de 32 alunos com idade de 15 a 19 anos.

O curso foi elaborado com carga horária de 20 horas (que foi distribuída ao longo de dez semanas, sendo, portanto, duas horas de aulas semanais). O objetivo principal da disciplina foi o de apresentar aos estudantes as principais estruturas de uma linguagem de programação e de praticar técnicas utilizadas na construção de algoritmos, como é o caso do uso da abstração, depuração de erros, testes e melhoria de algoritmos simples. O planejamento das aulas e exercícios manteve constantemente o cuidado em preservar os níveis cognitivos definidos pela Taxonomia de Bloom. O trabalho de Jesus e Raabe [21], que trata da interpretação dessa Taxonomia para o contexto do ensino introdutório de programação, foi bastante inspirador para a produção de exercícios e de materiais que estimulassem corretamente as atividades dos estudantes em sala de aula, respeitando seus passos de aprendizagem.

Cada aula teórica foi seguida de duas aulas práticas, onde os estudantes foram estimulados a praticar os comandos do Scratch, a desenvolver capacidades relacionadas à descoberta de erros nos códigos, ao trabalho colaborativo (completar códigos parcialmente implementados) e a criar projetos usando a sua criatividade, percebendo e se expressando através da construção de animações sobre aquilo o que estava à sua volta.

Apesar da existência de quatro turmas com professores diferentes, a produção dos planos de curso aconteceu através de um processo iterativo-incremental, resultante da troca de experiências dos professores que relatavam o contato semanal com suas turmas. Dessa maneira, foi possível ajustar os planos de forma que todos seguissem o mesmo planejamento.

Em relação à avaliação das turmas, o mesmo ocorreu e os exercícios de fixação foram repetidos entre as turmas para que se pudesse identificar as disparidades de aprendizagem entre elas. Um ambiente colaborativo foi estabelecido através de uma lista de discussão para que as experiências fossem trocadas semanalmente entre os professores e criou-se um repositório de conteúdo, que pôde ser acessado através de uma conta do Dropbox.

Ainda para efeito de avaliação de aprendizagem e também, como parte da metodologia que buscou engajar os alunos, foi organizada uma olimpíada de programação, detalhada na Seção 4.

\section{A Olimpíada Interna de Programação com Scratch (OIPS)}

O objetivo da OIPS foi estabelecer um ambiente motivacional entre os estudantes que compunham diferentes turmas e divulgar a existência de algumas competições nacionais, lhes informando sobre alguns eventos nos quais eles poderiam participar mesmo ainda cursando o ensino médio, como é o caso da Olimpíada Brasileira de Informática (OBI).

A OIPS também foi uma oportunidade de identificar resultados preliminares de aprendizagem dos alunos e as suas principais dificuldades. Logo, como a competição foi planejada para funcionar como um mecanismo de avaliação, buscou-se identificar que possíveis habilidades poderiam estar sendo desenvolvidas com os estudantes. Para tanto, procurou-se estabelecer desafios que explorassem a capacidade dos alunos em: utilizar corretamente as estruturas existentes em uma linguagem de programação, no caso, no Scratch; identificação de erros no código (depuração), leitura e interpretação de códigos de tercei- 
ros e codificação em pares, o que ocorreu a partir de trechos de códigos inicialmente implementados pela equipe.

A olimpíada foi realizada em uma única modalidade e os alunos competiram individualmente. $\mathrm{O}$ ambiente utilizado no momento da OIPS reproduziu um cenário comum de uma maratona de programação. A prova foi composta por cinco questões, as quais possuíam diferentes níveis de dificuldade técnicas, desde desafios simples de lógica até implementações completas que exigiam raciocínio elaborado e criatividade. Cada questão teve seu peso definido em função da sua complexidade. A competição teve duração de três horas e contou com a participação de 25 estudantes.

Para que seja possível entender como diferentes habilidades e técnicas de programação puderam ser exigidas na OIPS, e como elas foram o reflexo do que aconteceu ao longo das aulas do curso descrevemos em detalhes cada questão utilizada na competição nas subseções que seguem.

\subsection{Questão 1: Ordenação de instruções}

A ideia da questão "Ordenando as instruções" foi baseada em uma estratégia utilizada para produção de questões para o ensino fundamental, onde o professor apresenta um conjunto de palavras desordenado para os alunos, os quais devem criar frases com sentido real usando o conjunto fornecido.

Usando uma analogia desse tipo de questão, foram fornecidos vários fragmentos de programação para os participantes. As estruturas utilizadas foram explicadas durante as aulas, mas foram empregadas erroneamente no código fornecido na competição.

Esta questão exigia que o aluno identificasse que comandos eram imperativos para a correta implementação do código e também que ordenasse os comandos de forma que o código passasse a executar uma ação com sentido (Figura 2). O intuito desse desafio foi o de avaliar o grau de abstração dos alunos com relação ao que era necessário para a solução do problema, que é uma atitude fundamental para a formação de um bom programador.

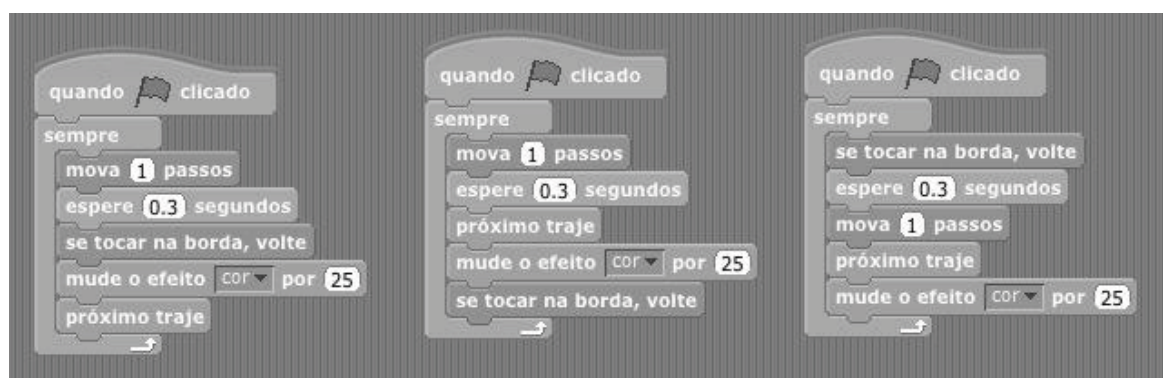

Figure 2: Código utilizado na questão Ordenação de instruções

Para executar a questão, um conjunto de regras foi definido: i. só estava permitido utilizar códigos que faziam parte dos comandos distribuídos, ii. nem todos os comandos fornecidos eram necessários para a construção da solução e iii. a ordenação dos comandos não era única, visto que existia mais de uma maneira de implementar um determinado algoritmo.

Para a pontuação da questão, durante a construção do algoritmo era essencial que o mesmo fosse o mais limpo possível. Os alunos aplicaram conceitos trabalhados durante as aulas que tratavam (de maneira muito superficial) do assunto melhoria de algoritmos, mas que despertavam a importância deste assunto para a Ciência da Computação. A avaliação da questão foi realizada através da criatividade utilizava durante a codificação, se a solução fornecida obedecera ao esperado e se o código produzido utilizara apenas os comandos necessários.

\subsection{Questão 2: Reproduza a animação}

Para resolver esta questão o competidor teve acesso a um vídeo contendo uma animação implementada no Scratch. Depois, solicitou-se que o aluno reproduzisse essa animação utilizando estruturas e comandos existentes no ambiente de programação. Dessa maneira, o conceito de uma especificação pôde ser utilizado com os alunos de maneira lúdica.

Esse desafio teve como objetivo apurar a capacidade dos alunos em seguir uma especificação, identificar, analisar e implementar uma solução para um problema com um resultado pré-definido, capacidade essa muito exigida em olímpiadas de programação. A animação continha características importantes que deveriam ser bem analisadas para a sua correta codificação, tais como: uso de estruturas de repetição e o sincronismo no diálogo existente entre seus os personagens.

Definiu-se que esta questão possuía nível intermediá- 
rio de dificuldade e para a sua análise considerou-se se a solução fornecida contivera ou não todos os detalhes necessários para a correta reprodução do vídeo fornecido aos competidores.

\subsection{Questão 3: Jogo de toca}

O jogo de toca é uma brincadeira infantil muito conhecida. De modo geral, o jogo consiste em dois tipos de jogadores: um personagem, que é o capturador e busca outros participantes do jogo, que devem evitar ser capturados. Na Olimpíada do Scratch foi solicitado que os alunos programassem parte desse jogo como um desafio para a competição. O objetivo principal dessa questão foi avaliar o conhecimento dos competidores em relação aos comandos relacionados às estruturas de controle do Scratch e os de aparência.

Foi disponibilizado para cada competidor um trecho de código do jogo, restando a ele apenas completar o comportamento que faltava. No código fornecido já estava implementada a movimentação de um personagem, a fuga do outro personagem e o sistema de pontuação, responsável pela alteração do placar.

Esperava-se dos competidores que eles montassem a estrutura condicional que permitiria a reação dos personagens conforme as regras que foram estipuladas no início do jogo:

i. Quando a pontuação do jogador fosse zero um personagem deveria emitir uma mensagem informando que o jogo estaria começando.

ii. Quando o placar atingisse 10 pontos o valor deveria ser informado e lançada uma mensagem incentivando o jogador continuar a jogar.

iii. Aos 15 pontos ele deveria emitir um aviso informando que o jogo estava finalizado, fazendo com que outro personagem sumisse.

A Figura 3 ilustra um código implementado por um dos participantes da competição. É importante que se perceba que ele utilizou inúmeras estruturas de controle e repetição, assim como o uso do conceito de variáveis. Essa questão foi classificada com nível de dificuldade intermediário. A avaliação da mesma ocorreu através da análise da criatividade durante a codificação do competidor e se o seu código criado atendera às condições exigidas.

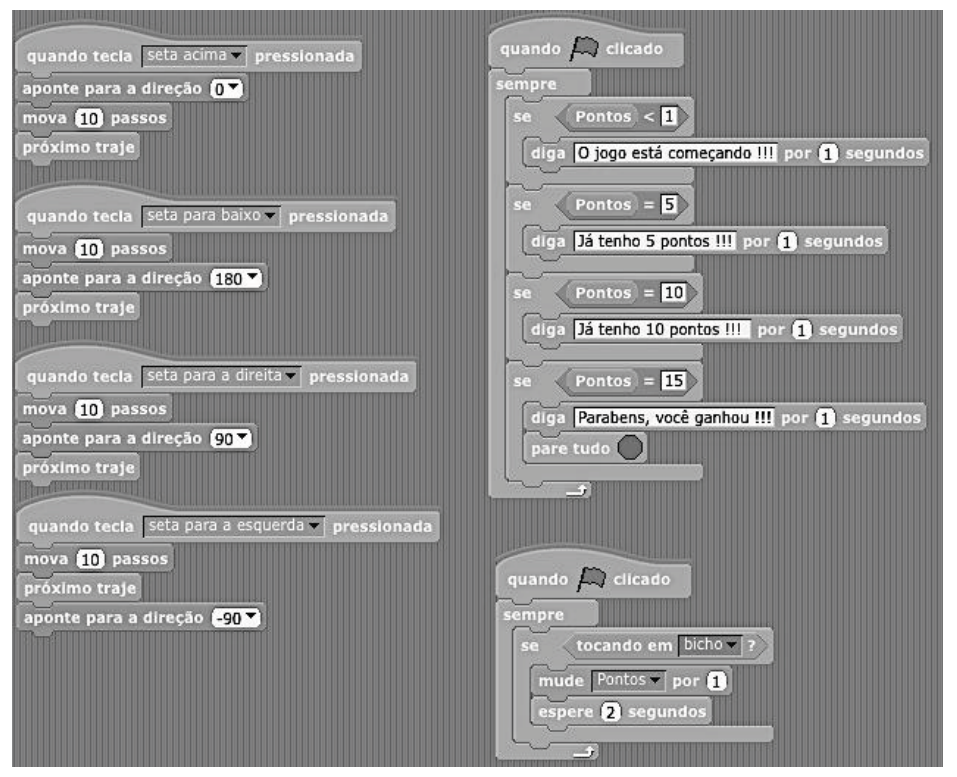

Figure3: Trecho de código implementado por um participante da OIPS 


\subsection{Questão 4: O fantástico sapo mágico}

A questão o fantástico sapo mágico foi apresentada aos alunos como sendo um sapo inteligente, capaz de realizar algumas operações básicas matemáticas: soma, subtração, divisão, multiplicação e raiz quadrada. A cada competidor foi fornecido o código que realizava quatro dessas operações (Figura 4). A questão exigia que o participante fosse capaz de depurar o código, descobrir que operação não estava implementada e fornecer a implementação faltante.

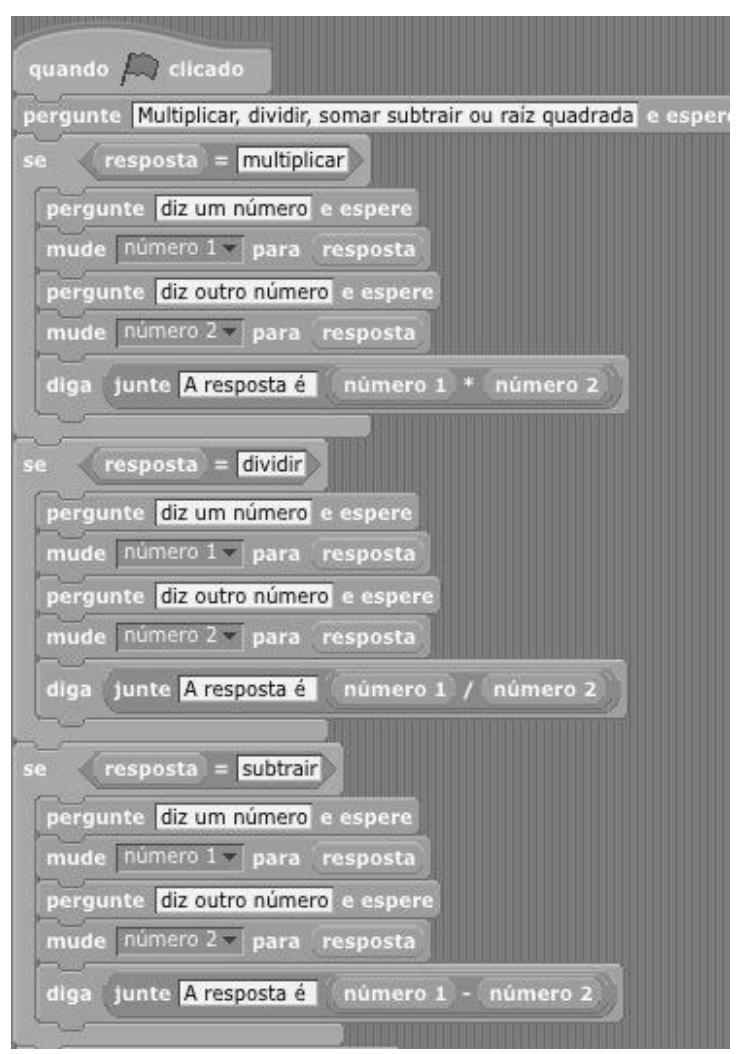

Figure 4: Trecho de código da questão o fantástico sapo mágico

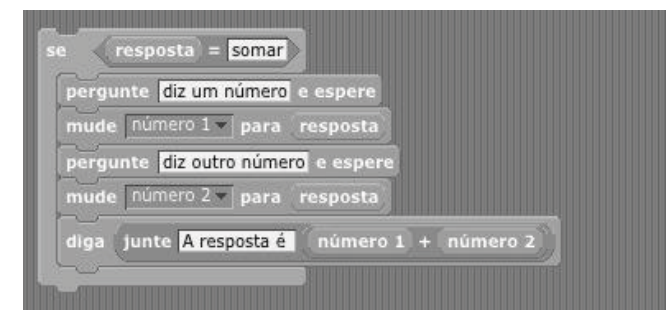

Figure 5: Código de uma soma implementado por um participante

Para que a questão fosse realizada com sucesso era necessário que o aluno tivesse um bom conhecimento dos comandos de controle, sensores, operadores e variáveis e o mais importante: que os alunos soubessem ler e enten- der cada parte do código. Então o aluno só completava a questão se conseguisse fosse capaz de identificar que a operação de soma estava faltando e que a completasse corretamente. A Figura 5 mostra um código implementado por um dos participantes da competição.

A atividade foi classificada com nível de dificuldade avançado. Em relação ao julgamento de desempenho, este foi analisado ao se verificar se os alunos identificaram, compreenderam e resolveram o erro inserido no desafio.

\subsection{Questão 5: Seja criativo}

Este quesito tinha como ideia principal a liberdade de criação. Com base nesse princípio esta questão era a oportunidade dos alunos demonstrarem o quanto conseguiram aprender durante o curso. Tendo como regra fundamental utilizar sua criatividade, era exigido do aluno que o mesmo reproduzisse alguma lembrança, desejo ou que imaginasse alguma história e reproduzisse com a maior quantidade de detalhes possível através de técnicas e comandos aprendidos no curso.

Esta questão foi classificada com nível de dificuldade avançado. Por ser uma questão muito aberta, onde o aluno poderia seguir qualquer caminho, foi necessário estabelecer alguns critérios para sua avaliação. Buscou-se avaliar os competidores segundo os seguintes critérios: controle dos elementos de repetição e de controle, destreza com os movimentos, mudança de trajes, sincronia nos diálogos, uso correto das cores, associação da história com o plano de fundo, criação de objetos e/ou personagens, utilização dos personagens disponíveis no ambiente e originalidade.

\subsection{Desempenho dos participantes na OIPS}

Como foi mencionado, além de servir como um elemento motivacional, a competição objetivou avaliar se a metodologia utilizada havia sido homogênea para todas as turmas do curso. A análise do desempenho dos participantes para os quatro primeiros desafios revelou os dados que estão apresentados na Tabela 1.

\begin{tabular}{|c|c|c|c|}
\hline Questão & Concluído & Parcialmente & Não concluído \\
\hline 1 & $88 \%$ & $12 \%$ & $0 \%$ \\
\hline 2 & $100 \%$ & $0 \%$ & $0 \%$ \\
\hline 3 & $75 \%$ & $25 \%$ & $0 \%$ \\
\hline 4 & $88 \%$ & $12 \%$ & $0 \%$ \\
\hline
\end{tabular}

Tabela 1: Desempenho dos participantes em 4 questões da competição

Pode-se observar que praticamente todos os alunos conseguiram atingir os mesmos resultados para todas as questões, o que validou a metodologia de trabalho utilizada, no que se refere ao seu caráter pedagógico. Ainda 
de acordo com a tabela pode-se observar que cerca de $90 \%$ dos competidores conseguiu concluir satisfatoriamente quatro dos cinco desafios propostos. Nenhum competidor deixou alguma questão sem implementar. $\mathrm{O}$ desenvolvimento de boas práticas de programação, como é o caso da leitura e interpretação de código alheio, de depuração e correção de erros, além da implementação de algoritmos simples, durante as aulas foram os subsídios para este resultado.

Como a Questão 5 (Seja Criativo) abriu diversas possibilidades de implementação, para a avaliação dessa questão foram definidos critérios que permitiram caracterizar as estruturas mais comuns nas respostas fornecidas pelos participantes, bem como, o uso da criatividade a partir dos recursos disponíveis no ambiente, como é o caso dos controles para movimentação e aparência dos personagens.

A Tabela 2 ilustra uma possível distribuição para o desempenho dos participantes. A coluna X representa a não utilização de um determinado componente na solução implementada. A coluna $\mathrm{K}$, por sua vez, representa o outro extremo, que é a utilização avançada desse componente.

\begin{tabular}{|l|c|c|c|c|}
\hline Critérios de uso & $\mathbf{x}$ & $\mathbf{Y}$ & $\mathbf{z}$ & $\mathbf{K}$ \\
\hline Elementos de Repetição & $0 \%$ & $25 \%$ & $50 \%$ & $25 \%$ \\
\hline Domínio Condicional & $24 \%$ & $38 \%$ & $0 \%$ & $38 \%$ \\
\hline Mudança de Trajes & $12 \%$ & $25 \%$ & $38 \%$ & $25 \%$ \\
\hline $\begin{array}{l}\text { Destrezas com os mo- } \\
\text { vimentos }\end{array}$ & $0 \%$ & $25 \%$ & $63 \%$ & $12 \%$ \\
\hline Controle no Diálogo & $0 \%$ & $50 \%$ & $38 \%$ & $12 \%$ \\
\hline Cores & $12 \%$ & $25 \%$ & $63 \%$ & $0 \%$ \\
\hline $\begin{array}{l}\text { Associação da história com o } \\
\text { plano de fundo utilizado }\end{array}$ & $12 \%$ & $38 \%$ & $50 \%$ & $0 \%$ \\
\hline $\begin{array}{l}\text { Originalidade ao criar e } \\
\text { utilizar objetos }\end{array}$ & $12 \%$ & $50 \%$ & $38 \%$ & $0 \%$ \\
\hline Utilização de Sprites & $0 \%$ & $63 \%$ & $25 \%$ & $12 \%$ \\
\hline Criatividade & $12 \%$ & $50 \%$ & $13 \%$ & $25 \%$ \\
\hline MÉDIA & $\mathbf{8 , 4 \%}$ & $\mathbf{3 8 , 9 \%}$ & $\mathbf{3 7 , 8 \%}$ & $\mathbf{1 4 , 9 \%}$ \\
\hline
\end{tabular}

Tabela 2. Desempenho dos participantes na questão Seja criativo, onde: $\mathrm{X}$ representa um recurso que não foi utilizado; $Y$ representa um recurso foi utilizado de forma básica; $\mathrm{Z}$ representa um recurso que foi utilizado de forma intermediária e $\mathrm{K}$ um recuso utilizado de forma avançada.

Em se tratando de aspectos mais técnicos, percebe-se a partir dessa tabela que a maioria dos participantes conseguiu utilizar corretamente as estruturas do Scratch para imple- mentar o comportamento que desejavam. Os itens que causaram maiores penalidades na avaliação estavam relacionados ao uso da criatividade e da originalidade das soluções. Comportamento este que reproduz o pouco contato que os estudantes possuem com o hábito de criar novas coisas sozinhos, muito provavelmente.

Finalizada a competição, a equipe solicitou que os competidores relatassem a visão que possuíam sobre a Computação antes de participarem do curso. As respostas mais comum relacionaram-se à visão que eles possuíam sobre a programação ser uma tarefa extremamente difícil e entediante. Quando perguntados sobre a motivação de continuar aprendendo a programar, $80 \%$ disseram desejar continuar aprendendo outras linguagens de programação.

O questionário também conseguiu refletir que o conhecimento técnico que os alunos adquiriram em relação às estruturas mais comuns, presentes na maior parte dos algoritmos, como é o caso de variáveis, funções, dispositivos de entrada e saída, laços e controle, pôde ser suficiente para que eles pudessem aprender novas linguagens de programação no futuro.

\section{Considerações finais e estado atual do trabalho}

Iniciar estudantes em programação deve ser um processo que transfira emoções positivas para o aprendiz, para que lhes seja possível construir a autossuficiência ideal para lidar com os diferentes problemas que surgirão quando estiverem escrevendo algoritmos. Este é um aspecto de extrema importância, principalmente, quando se trata de ensinar aos jovens as habilidades de programação.

Assim, como mencionado neste artigo, a presença de bons programadores não é suficiente para despertar o interesse de novatos em programação. É necessário entender como utilizar mecanismos que possam engajar os alunos para que o fluxo de aprendizagem seja mantido e eles possam enxergar o potencial das tecnologias a partir de uma nova perspectiva. E mais, que possam se enxergar capazes de criar novas coisas a partir da fluência em tecnologias.

O projeto demonstrou que apesar das inúmeras deficiências que os estudantes possuíam e que estavam relacionadas à escrita, leitura e fundamentação lógico-matemática, foi possível ensinar e aprender os conceitos básicos de programação, ao passo que se aprendia também sobre o mundo através da própria programação.

Em relação à experiência com os participantes desse projeto, percebe-se que eles estão se apropriando das informações necessárias para entender o que acontece em um curso superior na área de Computação. Tecnicamente, o conhecimento adquirido pelos estudantes lhes permitiu 
entender as diversas variáveis que influenciam a construção de algoritmos e os modelos de trabalho, que muitas vezes exigem que o programador trabalhe em códigos construídos por outras pessoas, que contém erros, que por sua vez, precisam ser corrigidos. Assim, pôde-se tratar de forma superficial, mas bastante eficiente, os meandros que existem no desenvolvimento de um produto de software. Procurou-se explicar aos estudantes que diferentes linguagens de programação existiam para diferentes propósitos.

Muitos outros estudantes das escolas têm se interessado em aprender a programar, até porque é uma novidade no colégio que estimula curiosidade dos pares. Percebe-se também a aptidão de alguns alunos que participaram do curso e que têm mostrado grande potencial como programadores em espaços de aprendizagem, como é o caso do curso intermediário que aborda a linguagem Python. Provavelmente, as informações que receberam lhe serão uteis para ponderar a escolha por um curso superior. Por outro lado, há o caso dos alunos que perceberam que as atividades existentes na Computação são diferentes daquilo que imaginavam. Esses também estão sendo estimulados a conhecer outras áreas para que a escolha da sua profissão aconteça de maneira mais consciente.

Este projeto representa uma mudança na cultura de algumas escolas e o fortalecimento da formação dos estudantes da Licenciatura em Computação, que perceberam este projeto como um espaço fértil e promissor para a geração de novos conhecimentos e oportunidades de empreender na educação.

Atualmente, a $3^{\mathrm{a}}$ edição do curso introdutório de programação com Scratch está sendo iniciada, assim como, a $2^{\text {a }}$ edição do curso intermediário de programação com Python. Dois estudantes da escola que participaram das ações aqui relatadas prestaram vestibular para o curso de Licenciatura em Ciência da Computação e foram aprovados. O desempenho desses alunos na disciplina Introdução à programação está sendo monitorado pela coordenação de curso.

\section{Referências}

[1] A National Talent Strategy. Ideas for securing U.S competitiveness and economy growth. Microsoft Report. September, 2012.

[2] M. Resnick.Mother's Day, Warrior Cats, and Digital Fluency: Stories from the Scratch Online Community. In Proceedings of the Constructionism 2012 Conference: Theory, Practice and Impact, 52-58. Greece, 2012.

[3] P. Olson. Why Estonia Has Started Teaching Its First-Graders To Code. Disponível em: http://www.forbes.com/sites/parmyolson/2012/0 9/06/why-estonia-has-started-teaching-its-first-
graders-to-code/Acessadoem 02 de fevereiro de 2013.

[4] A. Tucker.Model Curriculum for K-12 Computer Science. Final Report of the ACM K-12 Task Force Curriculum Committee. Association for Computing Machinery (ACM),October, 2004.

[5] Bell T., Andreae P., Robins A. Computer science in NZ high schools: the first year of the new standards. In SIGCSE '12: Proceedings of the 43rd ACM technical symposium on Computer Science Education, pages 343-348, 2012.

[6] L. A. Sudol. Deepening Students' Understanding of Algorithms: Effects of Problem Context and Feedback Regarding Algorithmic Abstraction. Doctoral dissertation, Carnegie MellonUniversity, june, 2011.

[7] M.Saeli, J. Perreneti, W. M.G. Jochems, B. Zwane-waneveld. A Pedagogical Content Knowledgein programming education for secondary school: Perspective. In ICER'11 proceedings of the 7th international workshop on Computing Education Research. Volume 10 (1): 145146, 2011.

[8] G. Futschek, J. Moschitz: Learning AlgorithmicThinking with Tangible Objects Eases Transition to Computer Programming. In ISSEP 2011: 155-164. 5th International Conference on Informatics in Schools: Situation, Evolution and Perspectives, Bratislava, Slovakia, October 2629, 2011.

[9] L. Major, T. Kyriacou, P. Brereton. Experiences of prospective high school teacher susing a programming teaching tool. In Koli Calling11Proceedingsofthe 11th Kol iCalling International Conference on Computing Education Research, 126-131. 2011.

[10] Lima Ribeiro et. al. (2011). "LEW: Laboratório de Engenharia Web para ensino, pesquisa e extensão". In: II Encontro Nacional de Informática e Educação, Campus Cascavel - PR.

[11] L. Grandell, M. Peltomaki, R. Back, T. Salakoski. Why complicate things? Introducing programming in high school using Python. In ACE'06 proceeding of the $8^{\text {th }}$ Australasian Conference on Computing Education. Volume 52: 71-80, 2006.

[12] D. L. Marques, L. F. S. Santos, M. A. de A. Silva et al. Atraindo Alunos do Ensino Médio para a Computação: Uma Experiência Prática de Introdução à Programação utilizando Jogos e 
Python. In XXII Simpósio Brasileiro de Informática na Educação- XVII Workshop de Informática na Escola, Aracaju, 1138 - 1147, 2011.

[13] C. E. Rapkiewicz, G. Falkembach, L. Seixas et al. Estratégicas pedagógicas no ensino de algoritmos e programação associadas ao uso de jogos educacionais. In RENOTE - Novas Tecnologias da Educação, v.4, n 2, 2006.

[14] N. Calder. Using Scratch: An Integrated Problem-Solving Approach to Mathematical Thinking. In Australian Primary Mathematics Classroom, v15 n4 p9-14. 2010.

[15] L. Young-Jin. Scratch: Multimedia Programming Environment for Young Gifted Learners. In Gifted Child Today, Volume 34(2): 26-31. 2011.

[16] D. Thomas, J. S. Brown. A New Culture of Learning: Cultivating the Imagination for a World of Constant Change. Createspace Independente Publishing Platform. 2011.

[17] M. Resnick, E. Rosenbaum. Designing for Tinkerability. Design, Make, Play: Growing the Next Generation of STEM Innovators, 163-181. Routledge. 2013.

[18] C. Kelleher, R. Pausch. Lowering the Barriers to Programming: A Taxonomy of Programming Environments and Languages for Novice Programmers. In ACM Computing Surveys, v. 37, n. 2, 83-137, 2005.

J. Maloney, M. Resnick, N. Rusk, B. Silverman,

[19] E. Eastmond. The Scratch Programming Language and Environment. In ACM Transactions on Computing Education (TOCE), vol. 10, no. 4,November. 2010.

[20] P. D. Scaico, E. F. Corlett, L. F. Paiva et al. Relato da Utilização de uma Metodologia de Trabalho para o Ensino de Ciência da Computação no Ensino Médio. In Anais do Congresso Brasileiro de Informática na Educação - XVIII Workshop de Informática na Educação, ISSN: 2316-6541, Rio de Janeiro, 2012.

[21] E. A. Jesus, A. L. A. Raabe. Interpretações da Taxonomia de Bloom no Contexto da Programação Introdutória. In Anais do XX Simpósio Brasileiro de Informática na Educação. Santa Catarina, 2009.

[22]

Bell, T., Whitten, I., Fellows, M (2007) Computer Science Unplugged. Canterbury University. Nova Zelândia. Disponível em http://csunplugged.org. 